\title{
Economic Costs and Benefits of Healthy Eating
}

\author{
Tobenna D. Anekwe • Ilya Rahkovsky
}

Published online: 25 June 2013

(C) Springer Science+Business Media New York 2013

\begin{abstract}
Most Americans fail to meet federal dietary recommendations. This may be partly due to the costs of healthy eating. This article reviews the costs and benefits of healthy eating. On the cost side, we discuss food prices, food preparation and other time costs, transportation costs, psychological costs, costs of obtaining nutrition information, and costs of longer life expectancy. We do not summarize these costs with a single dollar value as the current literature does not provide estimates to support such quantification. In terms of benefits, we focus on five health conditions for which poor diet is a major risk factor: coronary heart disease, cancer, stroke, diabetes, and osteoporotic hip fractures. We estimate the benefits of healthy eating in the United States to be $\$ 114.5$ billion per year (in 2012 dollars) in medical savings, increased productivity, and the value of prolonged life that are associated with reductions in these five conditions.
\end{abstract}

Keywords Healthy diet · Costs $\cdot$ Benefits $\cdot$ Nutrition $\cdot$ Food prices $\cdot$ Obesity $\cdot$ Healthy eating

\section{Introduction}

Despite continued federal dietary guidance, Americans' diets are far from optimal [1••]. Understanding the costs and benefits of healthy eating is important for understanding how and why people choose their diets and how diet quality can be improved. While much of the public health and economics literature has concentrated on an isolated cost or benefit of healthy eating, this paper unifies all of the costs

T. D. Anekwe $(\bowtie) \cdot$ I. Rahkovsky

Economic Research Service, United States

Department of Agriculture, 355 E Street SW,

Washington, DC 20024, USA

e-mail: tanekwe@ers.usda.gov

I. Rahkovsky

e-mail: irahkovsky@ers.usda.gov and benefits that are relevant to decisions about healthy eating. We bring together recent literature from economics, medicine, public health, nutrition, and psychology to give a complete picture of the incentives and disincentives related to healthy eating patterns. In so doing, we consider both monetary and non-monetary factors. We define costs as the various costs that would be borne by individuals and society if people were to consume healthy diets; we define benefits as the value of the population health improvements that would occur if the US population consumed healthy diets. We focus on diet, so we abstain from in-depth discussion of obesity, which has multiple causes besides diet. This review is restricted to the English-language literature and most of the references cited are from 2008 or later.

In the remainder of this article, we first define healthy eating, then review the evidence on the costs and benefits of healthy eating, then conclude by discussing what these costs and benefits mean for future progress toward improving diet in the US population. Figure 1 presents a tree structure of the costs and benefits that are considered in this article.

\section{What Is Healthy Eating?}

This article defines healthy eating in accordance with the Dietary Guidelines for Americans. Every 5 years, the US government reviews and publishes the Dietary Guidelines, which are recommendations for a healthy diet for the US population. Designed for Americans aged 2 years and older, these guidelines focus on foods and beverages that help people "attain and maintain a healthy weight, promote health, and prevent disease" [2••]. As described by the Dietary Guidelines, healthy diets limit intake of sodium, saturated and trans fats, added sugars, and refined grains and emphasize consumption of nutrient-dense foods and beverages, especially vegetables, fruit, whole grains, fat-free or 


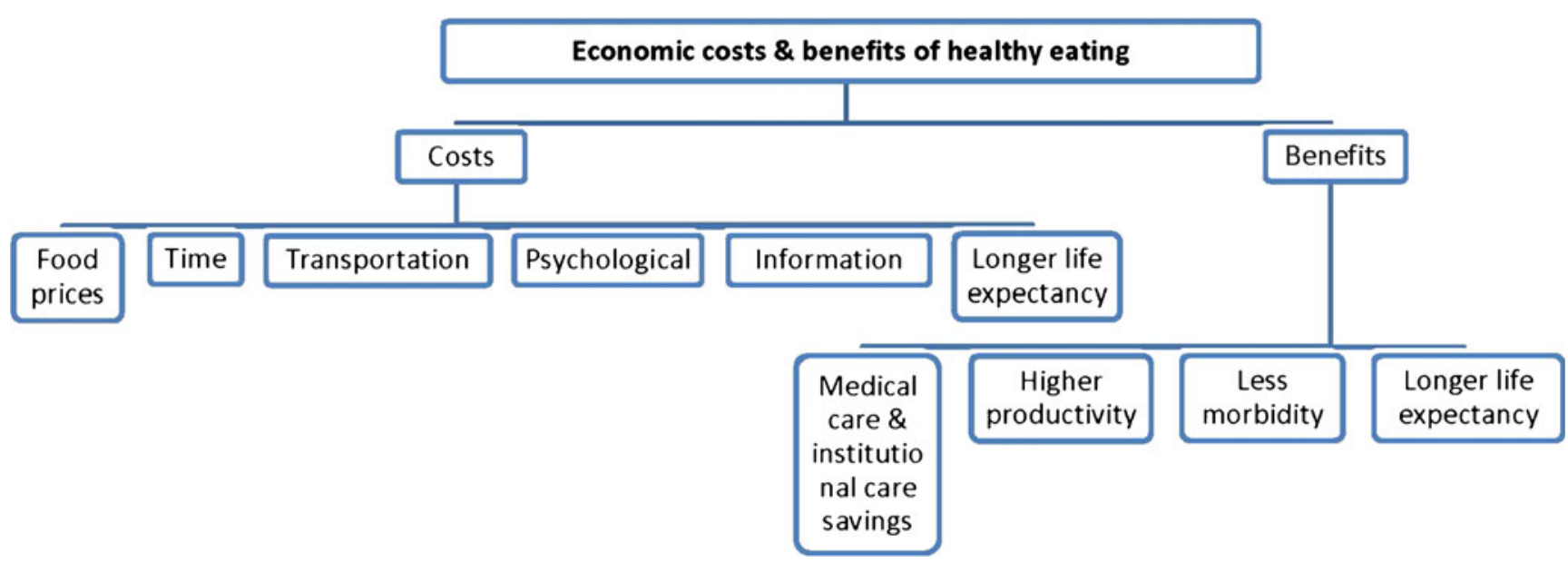

Fig. 1 Tree structure of the economic costs and benefits of healthy eating

low-fat milk and other dairy products, seafood, lean meats and poultry, eggs, beans and peas, and nuts and seeds. The Dietary Guidelines also draw attention to the dietary needs of specific population groups - for example, iron, folate, and seafood low in methyl mercury for fertile women; and sources

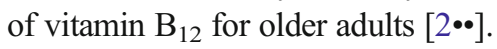

\section{Economic Costs of Healthy Eating}

\section{Food Prices}

\section{Declining Food Prices}

The real price of unhealthy foods has been declining for decades. An analysis of Consumer Price Index (CPI) data found that the real price of vending-machine food had dropped during $1978-2007$ by about $11 \%$ and soda had dropped by about $38 \%$, but the real price of fruit and vegetables had increased by about $18 \%$ [3]. Kuchler and Stewart [4] found that this price increase for fruit and vegetables has been driven by new produce items that incorporate labor-saving innovations (i.e., "prepared" produce such as washed and bagged spinach, broccoli florets, and baby-cut carrots). Their study analyzed price trends for unprepared produce that remained unchanged between 1980 and 2006 and showed that price trends for unprepared produce were similar to those for the less-healthy categories of snacks and desserts. This implies that consumers who wish to economize financially by purchasing unprepared (rather than prepared) produce face an additional time burden, as they bear the time cost of labor such as washing, peeling, cutting, and chopping the produce.

In addition, Lakdawalla and Philipson found that the price of food fell relative to the price of non-food items from 1976 to 1994 . This relative decrease in the price of food may have promoted overeating - one component of unhealthy eating - because the price of food rose less than inflation and was thus comparatively more affordable than other goods [5]. However, this trend of declining relative prices for food compared to non-food recently reversed as food prices surged in 2007 and 2008 [6].

\section{Total Cost of a Healthy Diet}

The Center for Nutrition Policy and Promotion's Thrifty Food Plan (TFP) is a national standard for a healthy diet at minimal cost and is used as the basis for maximum Supplemental Nutrition Assistance Program (SNAP; formerly the Food Stamp Program) allotments [7]. The TFP assumes that all food is prepared at home and minimizes deviations from currrent dietary patterns. The TFP finds that it is possible to eat healthy for low cost: the TFP budget in 2008 for a family of four was $\$ 136$ per week, of which $\$ 54$ (40\%) was earmarked for fruit and vegetables. However, adherence to the TFP imposes significant time costs (e.g., the need for bargain-hunting, traveling to and from the store, shopping, food preparation, cleanup). Because of these and other limitations, the TFP has been criticized as unrealistic $[8,9 \bullet]$.

Mediterranean dietary patterns are considered healthy, partly because they are associated with lower incidence of cardiovascular disease and lower rates of total mortality $[2 \bullet \bullet]$. The diet can be expensive [10], but Goulet et al. [11] found that middle- and upper-class consumers can achieve it (at no extra cost) by focusing on the lower-cost foods from the diet (e.g., pulses, legumes, nuts, dried fruit, canned fish) and buying less red meat, sweets, and fast foods in favor of healthy foods. However, Goulet et al. note that their study of the affordability of Mediterranean dietary patterns underrepresented people of low socioeconomic status, so no conclusions could be drawn about this population who may very well find such diets unaffordable. 


\section{Energy Density}

Energy-dense foods have a high ratio of calories per gram. Some researchers [12-15] argue that low-income consumers eat energy-dense foods (e.g., sweets, fast food, many snacks) because these foods are a cheaper source of calories than low-energy-density foods (e.g., fish, vegetables, fruit).

This claim has been contentious for a few reasons. First, the negative association between energy density (calories/gram) and cost per calorie (\$/calorie) may be spurious because of mathematical coupling, in which two variables that share a common component are compared [16]. Second, consumers with energy-dense diets in many cases spend the same amount of money on food as those with less-energy-dense diets [17] - so healthy eating is financially within reach for many consumers with energy-dense diets [17, 19••]. Third, if consumers chose foods based on cost per calorie, then the current trend of marketing foods with phrases such as "low-calorie" would not exist because such marketing claims would imply a poor bargain in terms of cost per calorie [18].

Weighing in on this debate is a recent study by Carlson and Frazão [19••] comparing various measures of food cost. The authors systematically compared the cost of healthy and unhealthy foods using three different cost metrics: price per 100 calories, price per 100 edible grams, and price per average portion. They found that healthy foods are actually less expensive than unhealthy foods when cost is measured as price per 100 edible grams or price per average portion. (Healthy foods were defined as those containing at least half a portion size of a Dietary Guidelines major food group and containing low to moderate amounts of saturated fats, added sugars, and sodium.) These findings underscore how important the choice of cost metric is when discussing the cost of healthy versus unhealthy foods.

\section{Diet Quality, Income, and Spending}

If healthy diets cost more, then consumers who spend more may eat healthier. The weight of the literature suggests that consumers who spend more on food tend to have healthier diets as meaured by the Healthy Eating Index [22, 23]. On the other hand, individuals who switch to a healthier diet-such as pregnant women following a low-glycemic diet [24] or obese children undergoing dietary treatment [25] — can do so without increasing their daily dietary costs.

If healthy diets are more expensive, then poorer people should have worse diets. Two systematic reviews [26, 27••] support this conclusion, finding that consumption of fruit and vegetables was positively associated with income. In England, the poor had worse diets and ate less fruit [28]. Poor consumers in the Phoenix, Arizona, area had worse diets, with the exception of lower quantities of saturated fat
[29]. On the other hand, a study using 2001-2002 National Health and Nutrition Examination Survey data showed that income had little influence on diet quality [30].

We conclude that there is a weak positive relationship between food spending and healthy diet. Although the TFP shows that it is possible to eat healthy at low (monetary) cost, adhering to the TFP guidelines imposes a high utility cost on individuals (such as time), so few people actually follow it. Economic theory suggests that people maximize utility subject to their budget constraint; as their budget constraint relaxes, people can purchase food that provides more utility in terms of health, leisure time, and palatability.

\section{Time Costs}

Time costs are driven by the opportunity cost of time. People may therefore eat healthier during brief recessions because joblessness increases leisure time, making it cheaper to undertake health-producing activities such as preparing healthy meals [31]. (However, during a long-lasting economic downturn, reductions in employment and income likely do not lead to healthier diets.)

Food prepared at home (FAH) is generally healthier than food away from home $[32,33]$ but it requires the time cost of activities such as grocery shopping, food preparation, and cleanup. These costs can be substantial. Economists have estimated the time costs of FAH by multiplying the opportunity cost of people's time (e.g., wage rate) by the number of hours spent in FAH activities. The daily household time cost of food preparation and cleanup was $\$ 20.43(50 \mathrm{~min})$ per SNAP household and \$21.62 (45 min) per non-SNAP household for people who performed housework and market work in 2003-2006 [34••]. Women have a higher time cost than men [35••].

Compared to the general population, SNAP participants have higher time costs and lower food input costs for FAH. But if SNAP participants were to follow the TFP, their daily time costs would have to increase further, from the current $\$ 8.66$ (38 $\mathrm{min})$ to $\$ 15.84(72 \mathrm{~min})$, while their monetary costs would marginally increase from $\$ 8.40$ to $\$ 8.56$ [35••]. That is, when total TFP time costs are monetized, they are 85 $\%$ higher than the cost of the food itself. In other words, the TFP is expensive once its associated time requirements are factored in $[8,35 \cdot 0]$. Households' actual SNAP participation status was not known in this study [35••], so the authors inferred SNAP participation from household demographics.)

Time is also required to develop cooking skills in the first place. Cooking skills may have deteriorated over the last several decades, leaving many people without the skill to time-efficiently prepare healthy meals [36]. (Declining confidence in one's skills may also be an issuel [37].) A study of young adults $18-23$ years old found that $18 \%$ of women and $23 \%$ of men cited their inadequate cooking skills as a barrier 
to food preparation; the study also found an association between cooking and healthy diet [38]. Cooking skill is positively associated with consumption of fruit and vegetables and negatively associated with consumption of convenience foods [39].

\section{Transportation Costs}

Consumers also incur transportation costs (e.g., gasoline) while traveling to grocery stores. People who live in food deserts - areas with limited access to affordable, healthy food - often incur higher transportation (and time) costs because supermarkets are far from their homes [40, 41]. Lowincome Americans are especially likely to live in food deserts, but evidence regarding socioeconomic disparities for other countries is scant [42].

Apart from grocery stores, access to healthy restaurants is also an issue. Restaurants in poorer Los Angeles County neighborhoods with a higher proportion of black residents have fewer healthy food options [43]. Higher concentrations of fast-food restaurants exist in poor and minority communities, although further work is needed to understand if and how access to fast food impacts dietary intakes and health outcomes [44].

\section{Psychological Costs}

This section reviews the psychological costs of healthy eating - that is, the psychological stress caused by healthy eating or the pursuit of healthy eating.

Habit, convenience, preferences, and taste are important determinants of a diet. Taste is enhanced by fat, sugar, and sodium, which are prevalent in many unhealthy products $[45,46]$. Food marketing caters to consumers' preferences for these substances - and stimulates their demand for these products - by developing foods designed to hook consumers and by advertising especially to children $[47,48]$.

Perception also affects dietary behavior. When consumers see information touting the healthiness of a food, they often assume that the food has an inferior taste, and this assumption decreases their enjoyment of the product $[49,50]$. When consumers are told that a food is healthy, they perceive it to be low in calories, which leads to overeating [51]. Large portions increase the psychological costs of healthy diet as consumers are tempted to finish their portions, leading them to overeat [52]. Furthermore, food vendors tend to supersize portions as the marginal cost of adding food to the portion is low [52]. Competition between food manufacturers can reduce incentives to introduce smaller portions and packages, especially many consumers have self-control problems with limiting their consumption [53].
Healthy behavior in one dietary area can be compensated for by unhealthy indulgence in another [51]. For example, consumers who take vitamins tend to eat less healthy, as they feel protected from negative health consequences [54]. Thus, healthy dietary behaviors may increase psychological costs by requiring greater self-discipline in other dietary areas.

One important feature of a healthy diet is that its benefits often occur in the distant future, while its costs (e.g., perceived inferior taste) occur immediately. Uncertainty about the future [55], impatience, and future discounting [56] all increase the psychological costs of healthy eating. One way to alleviate such problems is to introduce a lag between the day one selects and pays for groceries and the day one actually receives the food, as this delay leads to healthier purchases [57•].

Physiology and sociocultural norms also affect the cost of healthy eating. For individuals with strong self-control, consumption of unhealthy food leads to earlier satiation of the desire for such foods, reducing the psychological costs of eating healthy [58]. Genetic variations, as in the TAS2R38 gene, affect preferences for sugar, fat, fruit, and vegetables $[59,60]$. Choosing unhealthy food is easier when one is alone and anticipates dealing only with one's own guilt rather than with the shame of being witnessed [61]. Exposing children to healthy eating early in life creates good dietary habits, which reduces the psychological costs of healthy diet in the future [62].

Impulse shopping is associated with the purchase of unhealthy foods, so curbing impulsive purchases of unhealthy foods is a psychological cost of healthy eating. Consumers are more likely to purchase unhealthy foods when they pay by credit card rather than cash because paying in cash feels more painful and this pain can curb impulsive purchase decisions [63].

\section{Information Costs}

The information costs of healthy eating are the time and effort required to obtain nutrition information and update one's nutrition knowledge. Getting people to eat healthy may also require funding for education and informational campaigns designed to reorient people to a culture centered around healthy diets.

Researchers have identified three types of nutrition knowledge that promote healthy eating: 1) awareness that there is a link between diet and health (e.g., a link between saturated fat and heart disease), 2) knowledge of nutrition principles (e.g., recommendations on the percentage of calories that should come from fat), and 3) and knowledge of foods' specific nutrient content (e.g., which foods have more fiber, fat, or cholesterol) [64, 65].

Providing consumers with nutrition information at the point of purchase reduces their information costs. By 
requiring that nutrition labels have a standardized format and be easy to read, the 1990 Nutrition Labeling and Education Act (NLEA) helped consumers use nutrition information if they were already motivated to search for and process such information [66] and improved the diets of consumers who used nutrition labels [67, 68]. Providing nutrition information to consumers can cost firms as well, as in the case of firms being required to comply with the 2010 Patient Protection and Affordable Care Act, which mandates nutrition labeling of menu items.

After finding nutrition information, consumers must then analyze it. Consumers spend an average of $12.3 \mathrm{~s}$ acquiring nutrition information for each grocery item they select [70]. To calculate total time spent per shopper, this number would have to be multiplied by the number of grocery items that a shopper selects, and then added to the time cost for all other items that a consumer examines but does not ultimately select. This information cost may diminish somewhat over time as consumers learn the nutritional content of their favorite items but consumers may also have to continually spend time examining new products entering the market.

As nutrition science advances, consumers also face the cost of periodically updating their basic nutrition knowledge. Trans fat is a recent example. Consumers who were uninformed about the link between trans fat and poor health were unable to take advantage of the trans fat information that was added to the Nutrition Facts panel in 2006 [71, 72].

\section{Costs of Longer Life Expectancy}

Healthy diets extend life expectancy, which can result in extra costs due to age-related health conditions. The prevalence of chronic conditions (e.g., cardiovascular disease, diabetes, cancer, dementia, physical disability) increases with age [73].

\section{Economic Benefits of Healthy Eating}

The economic benefits of healthy eating are the value of the population health improvements that would be realized by shifting a population to an optimal diet, all else being equal. Shifting the US population to an optimal diet would reduce the prevalence of not only several risk factors-e.g., obesity, hypertension, high blood cholesterol, insulin resistance-but also myriad chronic diseases, including coronary heart disease (CHD), stroke, type 2 diabetes, osteoporosis, and cancers of the stomach, colon, rectum, esophagus, oral cavity, larynx, and pharynx $[74,75]$.

Healthy diets reduce morbidity and mortality and produce many kinds of economic benefits: lower medical care and institutional care costs, higher productivity, improved quality of life, and increased life expectancy. Our literature search did not reveal any work published in the last 10 years that estimates the costs of current eating patterns in the United States; however, a 1999 study by Frazão [76] estimates that healthier diets in the United States would annually prevent $\$ 70.9$ billion (in 1995 dollars) in medical costs, lost productivity, and the value of premature deaths associated with four health conditions: CHD, cancer, stroke, and diabetes. Three of these conditions - CHD, cancer, and stroke-were and still are among the top four causes of death in the United States, while diabetes was and still is the seventh leading cause of death (Table 1) [77-79]. Of the top ten causes of death, these four are the conditions for which diet (excluding alcohol) is a major risk factor $[75,80]$. In addition, the annual diet-related cost of a fifth condition-osteoporotic hip fractures - has been estimated to be at least $\$ 5.1$ billion in 1995 dollars, accounting for medical care, extendedtreatment facilities, and lost productivity (including productivity lost due to premature death) [81]. The sum of these diet-related costs of CHD, cancer, stroke, diabetes, and osteoporotic hip fractures is $\$ 76$ billion in 2005 dollars, or $\$ 114.5$ billion in 2012 dollars after updating with the "all items" CPI. (These costs include not only medical care but also other items such as lost productivity and the value of premature death, so we were conservative in applying the smaller "all items" CPI rather than the larger "medical care" CPI.)

This figure is likely an underestimate for a number of reasons. First, it does not include many diet-related conditions caused by overweight, osteoporosis, and hypertension, nor does it include neural tube defects. For example, overweight causes osteoarthritis, gallbladder disease, sleep apnea, and respiratory problems $[82,83]$. The medical and indirect costs of obesity are estimated at $\$ 139$ billion annually in 2003 dollars [84]; however, only the diet-related portion of these obesity costs are pertinent to this paper and some of these diet-related obesity costs have already been included because obesity contributes to the chronic diseases considered earlier. Also, our estimate does not include the diet-attributable costs of osteoporotic non-hip fractures, such as in the spine and wrist, among others [85]. Nor does our estimate account for the diet-attributable value of premature deaths due to osteoporotic fractures [86, 87] or for the fact that hypertension is a major contributor to end-stage renal disease [88]. Although folic acid supplements are taken by many reproductive-age women and the food supply is fortified with folic acid, some reproductive-age women still have low total folate intakes [89], which increases risk for neural tube defects among infants. Finally, healthy diets are associated with a lower likelihood of depression, although it is unclear in which direction the causality runs or if the causality is bidirectional [90].

In addition, the value of premature death is now typically measured by a much higher figure known as the value of a 
Table 1 Leading causes of death, United States, 1994 and 2010

\begin{tabular}{|c|c|c|c|c|c|}
\hline \multicolumn{3}{|l|}{1994} & \multicolumn{3}{|l|}{2010} \\
\hline Cause of death & $\begin{array}{l}\text { Number of } \\
\text { deaths }\end{array}$ & $\begin{array}{l}\text { Percentage } \\
\text { of all deaths }\end{array}$ & Cause of death & $\begin{array}{l}\text { Number } \\
\text { of deaths }\end{array}$ & $\begin{array}{l}\text { Percentage } \\
\text { of all deaths }\end{array}$ \\
\hline 1. Heart disease & 732,409 & 32.1 & 1. Heart disease & 597,689 & 24.2 \\
\hline Coronary heart disease & 481,458 & 21.1 & Coronary heart disease & $\mathbf{3 7 9 , 5 5 9}$ & 15.4 \\
\hline 2. Cancer & 534,310 & 23.4 & 2. Cancer & 574,743 & 23.3 \\
\hline 3. Stroke & 153,306 & 6.7 & 3. Chronic lower respiratory diseases & 138,080 & 5.6 \\
\hline $\begin{array}{l}\text { 4. Chronic obstructive pulmonary } \\
\text { diseases and allied conditions }\end{array}$ & 101,628 & 4.5 & 4. Stroke & 129,476 & 5.2 \\
\hline 5. Accidents and adverse effects & 91,437 & 4.0 & 5. Accidents & 120,859 & 4.9 \\
\hline 6. Pneumonia and influenza & 81,473 & 3.6 & 6. Alzheimer's disease & 83,494 & 3.4 \\
\hline 7. Diabetes & 56,692 & 2.5 & 7. Diabetes & 69,071 & 2.8 \\
\hline $\begin{array}{l}\text { 8. Human immunodeficiency } \\
\text { virus infection }\end{array}$ & 42,114 & 1.8 & $\begin{array}{l}\text { 8. Nephritis, nephrotic syndrome, } \\
\text { and nephrosis }\end{array}$ & 50,476 & 2.0 \\
\hline 9. Suicide & 31,142 & 1.4 & 9. Pneumonia and influenza & 50,097 & 2.0 \\
\hline 10. Chronic liver disease/cirrhosis & 25,406 & 1.1 & 10. Suicide & 38,364 & 1.6 \\
\hline All causes & $2,278,994$ & 100.0 & All causes & $2,468,435$ & 100.0 \\
\hline
\end{tabular}

Boldfaced are those health conditions for which diet (excluding alcohol) is a major risk factor

Sources: [76-79]

statistical life (VSL). Frazão applied a value of over $\$ 412,000$ for deaths at age 60 years and over $\$ 143,600$ for deaths at age 70 years whereas the majority of VSL estimates at the time [91] spanned a range starting around $\$ 3$ million per death in 1995 dollars. The VSL is designed to measure society's collective willingness to pay to prevent premature death for one unspecified person; it captures non-earnings income, the value of leisure, aversion to risk, and the value of avoiding pain and suffering [92]. Frazão notes that using the VSL to value diet-related premature deaths changes her \$70.9-billion cost of poor diet to some $\$ 474$ billion each year, or $\$ 714$ billion in 2012 dollars.

Furthermore, the prevalence of overweight, hypertension, and diabetes have continued to rise since the time of Frazão's work [93, 94]. Also, population growth and aging have increased the number of cases of diet-related chronic diseases $[95,96]$. Treatment and prevention strategies have changed. Although new treatments for cardiovascular disease and cancer have improved detection of cancer and extended patients' life [97-99], the treatments, at least in the case of cancer care, have been more costly [100], and longer lifespans due to treatment may mean longer time lived with disability, which also increases costs. These factors have all increased the dietrelated costs of unhealthy eating, or the diet-related benefits of healthy eating. Finally, medical care costs have risen faster than costs for "all items" so applying the "medical care" CPI to the medical care costs in Frazão's paper would have further increased our updated estimate.

In sum, the estimated annual economic benefits of healthy eating are $\$ 114.5$ billion in 2012 dollars. This estimate likely understates the true economic benefit of healthy eating in the United States. Although this estimate reflects the current published literature, data gaps remain. For example, since Frazão's work, medical costs and practices for various health conditions have changed, the population structure has aged, and obesity prevalence has increased. Future work on this topic should account for these factors and for a larger set of diet-related health conditions (including, for example, overweight, osteoporosis, hypertension, neural tube defects).

\section{Conclusions}

Economists assume that consumers are rational individuals who carefully compare all the costs and benefits of a decision before acting. In this article, we have described the costs and benefits of healthy eating from an individual and societal perspective. The price of healthy foods, while not a great barrier by itself, conspires with other barriers such as time constraints and consumer preferences for unhealthy foods, resulting in a high prevalence of unhealthy diets. This is especially a problem for money- and time-constrained consumers.

Food prices fell relative to non-food prices over the last several decades and this trend may continue in the future, so the monetary cost of healthy eating may be losing its relative importance. However, consumers have only $24 \mathrm{~h}$ a day. Healthy diets often require shopping, travel, preparation, and cleanup that can be a burden on time-poor consumers. 
Meanwhile, unhealthy fast foods and convenience foods are often nearby and readily available.

Convenience, consumer psychology and physiology, and the food environment affect the psychological costs of healthy eating. Many consumers are drawn to unhealthy foods, and this problem can be exacerbated by genetic predisposition and poor dietary habits acquired in childhood. The food environment- such as large portions, fast-food advertising, and food deserts - can increase the costs of healthy diet. Because the benefits of healthy eating occur in the distant future and enjoyment of unhealthy food starts immediately, consumers with strong self-control experience a lower cost of healthy diet.

None of these costs may matter if consumers do not know what a healthy diet is. Thus the cost of acquiring nutrition information is one of the first costs consumers incur on the path to a healthy diet.

Although we estimate the monetary value of the benefits of healthy eating, we do not do the same for the costs. Given the scope of this review, it was not feasible to monetize the costs as the current literature does not provide estimates to support such quantification.

If we compare the costs and benefits, we see that many of the costs (monetary, time, psychological) are borne by private individuals but the benefits are shared more evenly between private individuals and society as a whole. That is, the benefits impact not only private individuals in terms of their health care spending and quality of life but also society in terms of publicly funded programs like Medicare and Medicaid. As a result, individuals do not personally reap many of the social benefits of their personal healthy-eating habits. However, if the private benefits of healthy eating exceed the private costs, then consumers may be sufficiently motivated to eat healthy. Because many of the benefits of healthy eating are rooted in basic human physiology, we do not have much immediate control over them-but we as a society do have the ability to change the costs of healthy eating.

When consumers eat, they are responding to perceived costs and benefits of healthy eating. Perceived costs vary from person to person and within a person over time based on financial and time constraints, where one lives and works, and one's food preferences, among other factors. Although individuals face multiple costs at once, studies to date have tended to focus on just one or a few costs faced by consumers rather than taking a comprehensive view. Future research that assesses all costs of healthy eating and the distribution of these costs across subpopulations will enhance our understanding of dietary disparities and how people make dietary choices.

Acknowledgments We thank Elizabeth Frazão for helpful comments on an earlier version of this manuscript.

\section{Compliance with Ethics Guidelines}

Conflict of Interest Tobenna D. Anekwe currently works at USDA full-time.

Ilya Rahkovsky currently works at USDA full-time.

Human and Animal Rights and Informed Consent This article does not contain any studies with human or animal subjects performed by any of the authors.

\section{References}

Papers of particular interest, published recently, have been highlighted as:

- Of importance

•- Of major importance

1. • Hiza HAB et al. Diet quality of Americans differs by age, sex, race/ethnicity, income, and education level. J Acad Nutr Diet. 2012;113(2):297-306. This study used the Healthy Eating Index2005, a measure of diet quality in terms of conformance to the 2005 Dietary Guidelines for Americans, to describe the diet quality of Americans by varying sociodemographic characteristics in order to provide insight as to where diets need to improve.

2. • U.S. Department of Agriculture and U.S. Department of Health and Human Services, Dietary Guidelines for Americans, 2010. Washington, DC: U.S. Government Printing Office; 2010. Based on the most recent scientific evidence review, this document provides information and advice for choosing a healthy eating pattern-namely, one that focuses on nutrient-dense foods and beverages, and that contributes to achieving and maintaining $a$ healthy weight. By law, Dietary Guidelines for Americans is reviewed, updated if necessary, and published every five years. It is jointly created by the US Department of Agriculture and the US Department of Health and Human Services.

3. Christian T, Rashad I. Trends in US food prices, 1950-2007. Econ Hum Biol. 2009;7(1):113-20.

4. Kuchler F, Stewart H. Price Trends Are Similar for Fruits, Vegetables, and Snack Foods. Economic Research Report 55. Economic Research Service, U.S. Department of Agriculture; 2008.

5. Lakdawalla D, Philipson T. The growth of obesity and technological change: a theoretical and empirical examination. National Bureau of Economic Research; 2002.

6. Schnepf R. Consumers and Food Price Inflation. Congressional Research Service, Library of Congress; 2012.

7. Carlson A, et al. Thrifty Food Plan, 2006. Center for Nutrition Policy and Promotion; 2007. CNPP-19.

8. Rose D. Food stamps, the Thrifty Food Plan, and meal preparation: the importance of the time dimension for US nutrition policy. J Nutr Educ Behav. 2007;39(4):226-32.

9. - Davis GC, You W. The Thrifty Food Plan is not thrifty when labor cost is considered. J Nutr. 2010;140(4):854-7. This article points out that the TFP assumes that all food is prepared at home but it does not factor in food preparation time, which leads to an underestimate of the true cost of the TFP for low-income families. The study finds that once labor is included, the TFP is not very thrifty and the mean household falls short of the TFP guidelines even with adequate monetary resources. The authors conclude that the total labor associated with the TFP should be no greater 
than about six hours per week if it is to work for families, and one simple and practical policy solution is to develop more laborefficient recipes that satisfy the TFP.

10. Lopez CN, et al. Costs of Mediterranean and Western dietary patterns in a Spanish cohort and their relationship with prospective weight change. J Epidemiol Community Health. 2009.

11. Goulet J, Lamarche B, Lemieux S. A nutritional intervention promoting a Mediterranean food pattern does not affect total daily dietary cost in North American women in free-living conditions. J Nutr. 2008;138(1):54-9.

12. Drewnowski A. The cost of US foods as related to their nutritive value. Am J Clin Nutr. 2010;92(5):1181-8.

13. Drewnowski A, Darmon N. The economics of obesity: dietary energy density and energy cost. Am $J$ Clin Nutr. 2005;82(1):265S-73.

14. Waterlander WE et al. Energy density, energy costs and income-how are they related? Public Health Nutr. 2010;13(10):1599-608.

15. Maillot $M$ et al. Nutrient-dense food groups have high energy costs: an econometric approach to nutrient profiling. J Nutr. 2007;137(7):1815-20.

16. Lipsky LM. Are energy-dense foods really cheaper? Reexamining the relation between food price and energy density. Am J Clin Nutr. 2009;90(5):1397-401.

17. Frazao E. Reply to A Drewnowski et al. Am J Clin Nutr. 2009;90(3):702-3.

18. Lipsky LM et al. Fundamental misunderstanding of the relation between energy density $(\mathrm{kcal} / \mathrm{g})$ and energy cost $(\$ / \mathrm{kcal})$. Am J Clin Nutr. 2011;93(4):867.

19. • Carlson A, Frazão E. Are healthy foods really more expensive? It depends on how you measure the price. USDA Economic Research Service; 2012. Using the National Health and Nutrition Examination Survey, the Center for Nutrition Policy and Promotion food price database, and the USDA Food Patterns Equivalent Database, the authors measured food prices using three different metrics: price per 100 calories, price per 100 edible grams, and price per average portion. The authors found that healthy foods are cheaper than unhealthy foods when cost is measured with the latter two metrics.

20. Townsend MS et al. Less-energy-dense diets of low-income women in California are associated with higher energy-adjusted diet costs. Am J Clin Nutr. 2009;89(4):1220-6.

21. Bernstein AM et al. Relation of food cost to healthfulness of diet among US women. Am J Clin Nutr. 2010;92(5):1197-203.

22. Rydén PJ, Hagfors L. Diet cost, diet quality and socio-economic position: how are they related and what contributes to differences in diet costs? Public Health Nutr. 2011;14(09):1680-92.

23. Rehm CD, Monsivais P, Drewnowski A. The quality and monetary value of diets consumed by adults in the United States. Am J Clin Nutr. 2011;94(5):1333-9.

24. Cleary J et al. Does a low Glycaemic Index (GI) diet cost more during pregnancy? Nutrients. 2012;4(11):1759-66.

25. Raynor HA et al. A cost-analysis of adopting a healthful diet in a family-based obesity treatment program. J Am Diet Assoc. 2002;102(5):645-56.

26. Kamphuis $\mathrm{C}$ et al. Environmental determinants of fruit and vegetable consumption among adults: a systematic review. Br J Nutr. 2006;96(04):620-35.

27. •- Giskes $\mathrm{K}$ et al. A systematic review of studies on socioeconomic inequalities in dietary intakes associated with weight gain and overweight/obesity conducted among European adults. Obes Rev. 2010;11(6):413-29. This systematic review considered articles that examined the association between socioeconomic status (SES) and diet among European adults in 1990-2007. The review finds that SES has a small effect on consumption of fat and fiber. The most consistent difference in the literature is that low-SES consumers have low consumption of fruit and vegetables.

28. Tiffin R, Arnoult M. The demand for a healthy diet: estimating the almost ideal demand system with infrequency of purchase. Eur Rev Agric Econ. 2010;37(4):501-21.

29. Appelhans BM et al. Socioeconomic status, energy cost, and nutrient content of supermarket food purchases. Am J Prev Med. 2012;42(4):398-402.

30. Srinivasan CS. Food consumption impacts of adherence to dietary norms in the United States: a quantitative assessment. Agric Econ. 2007;37(2-3):249-56.

31. Ruhm CJ. Are recessions good for your health? Q J Econ. 2000;115(2):617-50.

32. Guthrie JF, Lin B-H, Frazao E. Role of food prepared away from home in the American diet, 1977-78 versus 1994-96: changes and consequences. J Nutr Educ Behav. 2002;34(3):140-50.

33. Variyam J. Nutrition labeling in the food-away-from-home sector: an economic assessment. USDA-ERS Economic Research Report, 2005(4).

34. - Raschke C. Food stamps and the time cost of food preparation. Rev Econ Househ. 2012;10(2):259-75. The authors examine the time costs of food preparation using the American Time Use Survey 2003-2006. They estimate the time cost of food preparation and cleanup for SNAP participants and for the general public.

35. •- Davis GC, You W. The time cost of food at home: general and food stamp participant profiles. Appl Econ. 2010;42(20):253752. This study examines the time costs food preparation and cleanup using the American Time Use Survey. The authors compare the amount of time Americans spend on these activities to what is required by the TFP.

36. Chenhall C. Improving cooking and food preparation skills: a synthesis of the evidence to inform program and policy development. 2010. Available at: www.hc-sc.gc.ca/fn-an/nutrition/childenfant/cfps-acc-synthes-eng.php. Accessed 17 April 2013.

37. Engler-Stringer R. Food, cooking skills, and health: a literature review. Can J Diet Pract Res. 2010;71(3):141-5.

38. Larson NI et al. Food preparation by young adults is associated with better diet quality. J Am Diet Assoc. 2006;106(12):2001-7.

39. Hartmann C, Dohle S, Siegrist M. Importance of cooking skills for balanced food choices. Appetite. 2013.

40. Besharov DJ, Bitler M, Haider SJ. An economic view of food deserts in the United States. J Policy Anal Manag. 2011;30(1):15376.

41. Ver Ploeg, M (Ed.). Access to affordable and nutritious food: measuring and understanding food deserts and their consequences: report to Congress. USDA Economic Research Service; 2009.

42. Beaulac J, Kristjansson E, Cummins S. A systematic review of food deserts, 1966-2007. Prev Chronic Dis. 2009;6(3).

43. Lewis LB, et al. African Americans' access to healthy food options in South Los Angeles restaurants. J Info. 2005;95(4).

44. Fleischhacker $\mathrm{S}$ et al. A systematic review of fast food access studies. Obes Rev. 2011;12(5):e460-71.

45. Drewnowski A, Almiron-Roig E. Human perceptions and preferences for fat-rich foods. In: J.-Montmayeur P, Coutre JL editors. Fat detection: taste, texture, and post ingestive effects. 2010. p. 265 266.

46. Tzieropoulos $\mathrm{H}$ et al. Dietary fat induces sustained reward response in the human brain without primary taste cortex discrimination. Front Hum Neurosci. 2013;7:36.

47. Cairns $\mathrm{G}$ et al. Systematic reviews of the evidence on the nature, extent and effects of food marketing to children: a retrospective summary. Appetite. 2013;62:209-15.

48. Chandon P, Wansink B. Does food marketing need to make us fat? A review and solutions. Nutr Rev. 2012;70(10):571-93. 
49. Freeman RP, Booth DA. Users of 'diet'drinks who think that sweetness is calories. Appetite. 2010;55(1):152-5.

50. Raghunathan R, Naylor RW, Hoyer WD. The unhealthy=tasty intuition and its effects on taste inferences, enjoyment, and choice of food products. J Market. 2006:170-84.

51. Finkelstein SR, Fishbach A. When healthy food makes you hungry. J Consum Res. 2010;37(3):357-67.

52. Dobson PW, Gerstner E. For a few cents more: why supersize unhealthy food? Market Sci. 2010;29(4):770-8.

53. Jain S. Marketing of vice goods: a strategic analysis of the package size decision. Market Sci. 2012;31(1):36-51.

54. Chiou W-B, Yang C-C, Wan C-S. Ironic effects of dietary supplementation illusory invulnerability created by taking dietary supplements licenses health-risk behaviors. Psychol Sci. 2011;22(8):10816.

55. Milkman KL. Unsure what the future will bring? You may overindulge: uncertainty increases the appeal of wants over shoulds. Organ Behav Hum Decis. 2012;119(2):163-76.

56. Huston SJ, Finke MS. Diet choice and the role of time preference. J Consum Aff. 2003;37(1):143-60.

57. • Milkman KL, Rogers T, Bazerman MH. I'll have the ice cream soon and the vegetables later: a study of online grocery purchases and order lead time. Market Lett. 2010;21(1):17-35. The authors conduct a laboratory experiment to estimate the impact of introducing a two-day delay between a consumer's food order and delivery. The authors find that a delay increases the percentage of healthy foods (vegetables) and decreases the percentage of unhealthy foods (ice cream) that consumers order.

58. Redden J, Haws K. Healthy satiation: the role of decreasing desire in effective self-control. J Consum Res. 2013.

59. Feeney E et al. Genetic variation in taste perception: does it have a role in healthy eating? Proc Nutr Soc. 2011;70(01):135-43.

60. Dotson CD, Babich J, Steinle NI. Genetic predisposition and taste preference: impact on food intake and risk of chronic disease. Curr Nutr Rep. 2012;1(3):175-83.

61. Chun H, Patrick VM, MacInnis DJ. Making prudent vs. impulsive choices: the role of anticipated shame and guilt on consumer selfcontrol. Adv Consum Res. 2007;34:715.

62. Cooke L. The importance of exposure for healthy eating in childhood: a review. J Hum Nutr Diet. 2007;20(4):294-301.

63. Thomas M, Desai KK, Seenivasan S. How credit card payments increase unhealthy food purchases: visceral regulation of vices. J Consum Res. 2011;38(1):126-39.

64. Blaylock $\mathrm{J}$ et al. Economics, food choices, and nutrition. Food Policy. 1999;24(2-3):269-86.

65. Rogers EM. Diffusion of innovations. New York: Free Press; 1983.

66. Balasubramanian SK, Cole C. Consumers' search and use of nutrition information: the challenge and promise of the Nutrition Labeling and Education Act. J Market. 2002;66(3):112-27.

67. Drichoutis A, Lazaridis P, Rodolfo J, Nayga M. Consumers' use of nutritional labels: a review of research studies and issues. Acad Market Sci Rev. 2006;10(9).

68. Variyam JN. Do nutrition labels improve dietary outcomes? Health Econ. 2008;17(6):695-708.

69. Federal Register. Food labeling: nutrition labeling of standard menu items in restaurants and similar retail food establishments. 2012. Available at: https://www.federalregister.gov/regulations/0910AG57/food-labeling-nutrition-labeling-of-standard-menu-items-inrestaurants-and-similar-retail-food-estab. Accessed 16 April 2013.

70. Moorman C. A quasi experiment to assess the consumer and informational determinants of nutrition information processing activities: the case of the Nutrition Labeling and Education Act. J Public Policy Mark. 1996;15(1):28-44.

71. Howlett E, Burton S, Kozup J. How modification of the nutrition facts panel influences consumers at risk for heart disease: the case of trans fat. J Public Policy Mark. 2008;27(1):83-97.
72. Kozup J, Burton S, Creyer EH. The provision of trans fat information and its interaction with consumer knowledge. J Consum Aff. 2006;40(1):163-76.

73. Rice DP, Fineman N. Economic implications of increased longevity in the United States. Ann Rev Public Health. 2004;25(1):45773.

74. Lock K et al. The global burden of disease attributable to low consumption of fruit and vegetables: implications for the global strategy on diet. Bull World Health Organ. 2005;83(2):100-8.

75. World Health Organization, Diet, Nutrition and the Prevention of Chronic Diseases: Report of a Joint WHO/FAO Expert Consultation, in WHO Technical Report Series No. 916. 2003, Geneva, Switzerland.

76. Frazão E. High costs of poor eating patterns in the United States. Chapter 1 in America's Eating Habits: Changes and Consequences. USDA Economic Research Service; 1999.

77. Centers for Disease Control and Prevention. Detailed tables for the National Vital Statistics Report "Deaths: Final Data for 2010". 2013. Available at: http://www.cdc.gov/nchs/data/dvs/deaths_2010_ release.pdf. Accessed 22 March 2013.

78. Centers for Disease Control and Prevention. Leading causes of death. 2013. Available at: http://www.cdc.gov/nchs/fastats/ lcod.htm. Accessed 22 March 2013.

79. Singh GK, Kochanek KD, MacDorman MF. Advance report of final mortality statistics, 1994. Monthly Vital Statistics Report. 1996;45(3, Supplement).

80. Yach D, et al. The global burden of chronic diseases: overcoming impediments to prevention and control. 2004;291(21):2616-22.

81. Barefield E. Osteopororsis-related hip fractures cost $\$ 13$ billion to \$18 billion yearly. Food Rev. 1996;19(1):31-6.

82. Bray GA. Health hazards of obesity. Endocrinol Metab Clin N Am. 1996;25(4):907-19.

83. Popkin BM, Kim S, Rusev ER, Du S, Zizza C. Measuring the full economic costs of diet, physical activity and obesity-related chronic diseases. Obesity Reviews. 2006;7(3):271-293.

84. Finkelstein EA, Ruhm CJ, Kosa KM. Economic causes and consequences of obesity. Annu Rev Public Health. 2005;26:239-57.

85. Cummings SR, Melton LJ. Epidemiology and outcomes of osteoporotic fractures. Lancet. 2002;359(9319):1761-7.

86. Johnell O, Kanis JA. An estimate of the worldwide prevalence, mortality and disability associated with hip fracture. Osteoporos Int. 2006;17(12):1726-33.

87. Johnell $\mathrm{O}$ et al. Mortality after osteoporotic fractures. Osteoporos Int. 2004;15(1):38-42.

88. Fields LE et al. The burden of adult hypertension in the United States 1999 to 2000: a rising tide. Hypertension. 2004;44(4):398 404.

89. Bailey RL et al. Total folate and folic acid intakes from foods and dietary supplements in the United States: 2003-2006. Am J Clin Nutr. 2010;91(1):231-7.

90. Kuczmarski MF et al. Higher Healthy Eating Index-2005 scores associated with reduced symptoms of depression in an urban population: findings from the Healthy Aging in Neighborhoods of Diversity Across the Life Span (HANDLS) study. J Am Diet Assoc. 2010;110(3):383-9.

91. Viscusi WK. The value of risks to life and health. J Econ Lit. 1993;31(4):1912-46.

92. Landefeld JS, Seskin EP. The economic value of life: linking theory to practice. Am J Public Health. 1982;72(6):555-66.

93. Cheung BMY et al. Diabetes prevalence and therapeutic target achievement in the United States, 1999 to 2006. Am J Med. 2009;122(5):443-53.

94. Mokdad A et al. The continuing epidemics of obesity and diabetes in the United States. JAMA. 2001;286(10):1195-200.

95. World Health Organization. World Health Report 2003: a vision for global health. Shaping the future; 2003. 
96. Eyre $\mathrm{H}$ et al. Preventing cancer, cardiovascular disease, and diabetes: a common agenda for the American Cancer Society, the American Diabetes Association, and the American Heart Association*†. CA Cancer J Clin. 2004;54(4):190-207.

97. Siegel R, Naishadham D, Jemal A. Cancer statistics, 2012. CA Cancer J Clin. 2012;62(1):10-29.
98. Jemal A et al. Cancer statistics, 2008. CA Cancer J Clin. 2008;58(2):71-96.

99. Ford ES et al. Explaining the decrease in U.S. Deaths from coronary disease, 1980-2000. N Engl J Med. 2007;356(23):2388-98.

100. Meropol NJ, Schulman KA. Cost of cancer care: issues and implications. J Clin Oncol. 2007;25(2):180-6. 